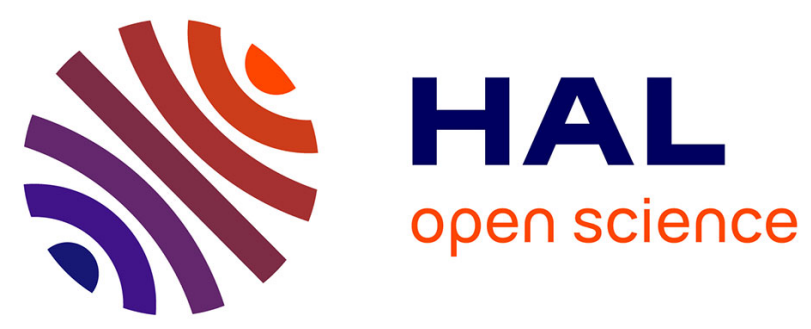

\title{
FLUX GROWTH, ANALYSIS AND CRYSTALLOGRAPHIC ASPECTS OF ALKALI RARE EARTH SULFIDES
}

\author{
A. Verheijen, W. van Enckevort, J. Bloem, L. Giling
}

\section{- To cite this version:}

A. Verheijen, W. van Enckevort, J. Bloem, L. Giling. FLUX GROWTH, ANALYSIS AND CRYSTALLOGRAPHIC ASPECTS OF ALKALI RARE EARTH SULFIDES. Journal de Physique Colloques, 1975, 36 (C3), pp.C3-39-C3-45. 10.1051/jphyscol:1975309 . jpa-00216279

\section{HAL Id: jpa-00216279 https://hal.science/jpa-00216279}

Submitted on 1 Jan 1975

HAL is a multi-disciplinary open access archive for the deposit and dissemination of scientific research documents, whether they are published or not. The documents may come from teaching and research institutions in France or abroad, or from public or private research centers.
L'archive ouverte pluridisciplinaire HAL, est destinée au dépôt et à la diffusion de documents scientifiques de niveau recherche, publiés ou non, émanant des établissements d'enseignement et de recherche français ou étrangers, des laboratoires publics ou privés. 


\title{
FLUX GROWTH, ANALYSIS AND CRYSTALLOGRAPHIC ASPECTS OF ALKALI RARE EARTH SULFIDES
}

\author{
A. W. VERHEIJEN, W. J. P. VAN ENCKEVORT \\ J. BLOEM and L. J. GILING \\ University of Nijmegen, Laboratory of Physics \\ Department of Solid State Chemistry, Toernooiveld, Nijmegen, Holland
}

\begin{abstract}
Résumé. - Un aperçu est présenté sur les méthodes de préparation destinées à obtenir des composés MTS ${ }_{2}$ de haute qualité avec, comme exemple typique, $\mathrm{KLaS}_{2}$. L'analyse montre invariablement la présence de petites quantités d'oxysulfide $\mathbf{T}_{2} \mathrm{O}_{2} \mathrm{~S}$.

Une analyse géométrique de la structure cristalline de la classe des sulfides ternaires à laquelle $\mathrm{KLaS}_{2}$ appartient mène à des expressions théoriques pour les axes hexagonaux $a_{\mathrm{h}}$ et $c_{\mathrm{h}}$ et pour les déplacements de sulfure attendus. Ces résultats théoriques correspondent de près aux valeurs expérimentales.

Abstract. - A survey is given of the preparation methods to obtain high quality MTS $_{2}$ compounds with $\mathrm{KLaS}_{2}$ as a typical example. The analysis invariably shows the presence of small amounts of the $\mathrm{T}_{2} \mathrm{O}_{2} \mathrm{~S}$ oxysulfide.

A geometrical analysis of the crystal structure of the class of ternary sulfides to which $\mathrm{KLaS}_{2}$ belongs leads to theoretical expressions for the hexagonal $a_{\mathrm{n}}$ - and $c_{\mathrm{n}}$-axes and for the expected sulfur shifts which are in close agreement with experimental values.
\end{abstract}

Introduction. - The ternary sulfides $\mathrm{MTS}_{2}$, in which $\mathbf{M}$ is an alkaline ion and $T$ a trivalent rare earth ion (e. g. $\mathrm{KLaS}_{2}$ ) were first reported by Ballestracci and Bertaut who studied the synthesis and crystallographic aspects of the $\mathrm{Li}, \mathrm{Na}$ and $\mathrm{K}$ compounds [1, 2]. In essence these sulfides were found to be stable either in a disordered $\mathrm{NaCl}$-structure when $1.08>r_{\mathrm{T}} / r_{\mathrm{M}}>0.95$ or to crystallize in the ordered $\mathrm{R} 3 \mathrm{3} m \alpha-\mathrm{NaFeO}_{2}$ structure $\left(\mathrm{D}_{3 \mathrm{~d}}^{5}\right)$ for $r_{\mathrm{T}} / r_{\mathrm{M}}<0.95$. Above $r_{\mathrm{T}} / r_{\mathrm{M}}=1.08$ the ternary sulfide does not exist. Tromme [3], who used another preparation method, was able to verify these stability regions. In addition, Bronger et al. [4] determined the lower limit of the ordered structure to be $r_{\mathrm{T}} / r_{\mathrm{M}}=0.62$ by extending the series to the rubidium and cesium compounds. Brüesch and Schüler [5] prepared some of these sulfides in single crystalline form and recorded their Raman spectra. From the observed phonon lines they could calculate the force constants for the $\mathrm{A}_{1 \mathrm{~g}}$ and $\mathrm{E}_{\mathrm{g}}$ modes. No further optical or electrical data about these compounds seem to be available.

Our interest in these compounds arose from the idea that these sulfides might be suited for a study of the defect chemistry. Since a good deal of information is available about defect chemistry of II-IV compounds, it is interesting to study the same kind of phenomena in compounds in which the di-valent ion is replaced by a combination of a monovalent and a trivalent ion. As in addition at least some of the rare earth ion containing crystals show an appreciable fluorescence, the optical and electrical properties should give valuable information about defects and/or deviation in stoichiometry.

1. Preparation and analysis. - A general condition for the study of defect chemistry is to have samples which, to start with, are in the purest possible form, only then a study of the defects themselves is likely to be successful. Our main object therefore was to find a way to produce the ternary sulfides in a pure, well defined and reproducible manner, starting of course with high quality chemicals. In their papers Ballestracci and Bertaut $[1,2]$ indicate several methods all initially based on gel formation to get an intimate mixing of the starting products. Although several attempts were undertaken and some modifications were introduced no satisfactory results were obtained in our laboratory by any of these methods. The yield was low and the reproducibility of the quality disappointing. Similar experiences were mentioned by Tromme [3].

For this reason it was decided to adopt the preparation method introduced by Tromme [3] and Brüesch and Shüler [5]. In this synthesis powders and/or crystals can be obtained by reacting rare earth oxide and alkaline carbonate in a stream of $\mathrm{H}_{2} \mathrm{~S}$ at high temperatures. The partial decomposition of $\mathrm{H}_{2} \mathrm{~S}$ at these high temperatures into hydrogen and sulfur together with the reaction of the oxide and carbonate into the corresponding sulfides, ends up in a mixture of rare earth sulfides and alkali polysulfides. In this flux the sulfides react to form the ternary compound. Since 
Brüesch and Schüler are not too specific in their reaction conditions, several temperature profiles and time regimes were tried in order to arrive at the desired end product. The result was that the best quality crystals and the largest sizes were obtained when a relatively high reaction temperature was combined with a large excess of alkali sulfide, a short reaction time and a short cooling period. Longer reaction times and slow cooling processes (down to 1 degree per hour) proved to be less satisfactory because of the fast evaporation of the alkali sulfide at the high reaction temperature. For instance good quality crystals of $\mathrm{KGdS}_{2}$ were obtained by the following procedure : $0.5 \mathrm{~g}$ of $\mathrm{Gd}_{2} \mathrm{O}_{3}$ and $15 \mathrm{~g}$ of $\mathrm{K}_{2} \mathrm{CO}_{3}$ (molar ratio $1: 79$ ) were intimately mixed by means of a ballmill. The mixture was placed in a pyrographic coated graphite boat of $9.5 \times 1.5 \times 1.5 \mathrm{~cm}^{3}\left(\mathrm{Al}_{2} \mathrm{O}_{3}\right.$ boats were readily attacked by the corrosive melt, while boats made of vitreous carbon did not seem to have advantages above the graphite boats). The boat with the reaction mixture is placed in a $\mathrm{Al}_{2} \mathrm{O}_{3}$ furnace tube, quality Pythagoras, which was provided with glass end pieces molten directly to the ceramic tube. In this way gas leakage could be completely eliminated. The furnace temperature was then raised to $830^{\circ} \mathrm{C}$, kept there for 2 hours, raised again to $1030^{\circ} \mathrm{C}$ and kept there again for 2 hours. During the whole process a flow of $\mathbf{H}_{2} \mathrm{~S}$ of $15 \mathrm{~g} / \mathrm{h}$ was used through the tube. The flux was cooled down spontaneously. After cooling, the flux of polysulfides, containing the ternary sulfides was dissolved in water and the remaining reaction products rinsed with water, alcohol, $\mathbf{C S}_{2}$, alcohol and ether, after which the resulting end product was dried at $120^{\circ} \mathrm{C}$. Transparent crystals up to $5 \times 5 \mathrm{~mm}^{2}$ and about $40 \mu$ thick were obtained in this way.

For the preparation of the $\mathrm{Na}$ and Li ternary sulfides the same molar ratios were used as for $\mathrm{KTS}_{2}$. The reaction temperature was $1250^{\circ} \mathrm{C}$ for the $\mathrm{Na}$ and $900^{\circ} \mathrm{C}$ for the $\mathrm{Li}$ compounds. The quality of the $\mathrm{Li}$ ternary sulfides was always poor. The reason has to be found in the high reaction temperature which is necessary for the conversion of the rare earth into the sulfide, which causes a high vapour pressure of $\mathrm{Li}_{2} \mathrm{~S}$. The stability of these crystals in air is good, some deterioration was found after a period of about two or three months. In a similar manner the powdered form could be achieved. Powdered $\mathrm{KGdS}_{2}$ was obtained by reacting the oxide-carbonate mixture at $900^{\circ} \mathrm{C}$ in a $\mathrm{H}_{2} \mathrm{~S}$ stream. The molar ratio rare earthalkali was $1: 15$. The same temperature was used for the powders containing $\mathrm{Li}$ and $\mathrm{Na}$ respectively.

Since the maximum size of the crystals prepared by any of the above mentioned methods never exceeds $5 \times 5 \mathrm{~mm}^{2} \times 40 \mu$ and larger crystals are more attractive, it was tried to grow crystals by vapour growth. According to Schäfer [6], the rare earth and the alkali can be transported by $\mathrm{AlCl}_{3}$-complex formation. Starting with $\mathrm{NaGdS}_{2}$ and $\mathrm{AlCl}_{3}$ in a closed silica tube, the transport was carried out from $700^{\circ} \mathrm{C}$ to $600^{\circ} \mathrm{C}$. The result was negative. It was then tried to favour the rare earth transport by adding some $\mathrm{J}_{2}$ next to the $\mathrm{AlCl}_{3}$. The final result again was disappointing : only $\mathrm{NaCl}$ was transported.

The reaction products were analysed according to standard methods [7]. From each compound also the $\mathrm{X}$-ray powder diffraction pattern was recorded which served as an additional analytical determination. All the analyses, except some for $\mathrm{KGdS}_{2}$, invariably showed that the reaction was not complete, i. e. that the reaction products contained an impurity which by means of X-ray spectra could be identified as the rare earth oxysulfide $\mathrm{T}_{2} \mathrm{O}_{2} \mathrm{~S}$. The impurity content varied considerably depending on the rare earth which was being used. The content of $\mathrm{T}_{2} \mathrm{O}_{2} \mathrm{~S}$ could be as high as $50 \%$ in the case of $\mathrm{KErS}_{2}$. High impurity levels are easily detected by the different colour of the oxysulfides and because of a different crystal habitus. The oxysulfides crystallize in octahedrally shaped cristals which are easily distinguished from the hexagonal platelets of the ternary sulfides. The oxysulfides are thermodynamically very stable compared with the sulfides $[8,9]$, which may explain their persistent occurrence. Even when the ternary sulfide was prepared from the elements themselves under rigorous exclusion of oxygen the oxysulfide still appeared to be present in the reaction product, presumably because of exchange with the $\mathrm{Al}_{2} \mathrm{O}_{3}$ tube or because of a trace impurity in the hydrogen sulfide. Thus, even under conditions which provide a low oxygen partial pressure the oxysulfide is present as a second phase.

A neutron diffraction spectrum obtained from a powder showed an even more unforeseen and creepy aspect, viz. according to the neutron diffraction pattern, some $\mathrm{T}_{2} \mathrm{O}_{2} \mathrm{~S}$ was present. An X-ray determination of the same sample did not show up any of the characteristic oxysulfide lines. The conclusion can only be that the inner part of some of the crystallites is composed of oxysulfide, covered by skin of the ternary sulfide. This is a serious reason to reject this powdered form of the ternary sulfides as a starting material for defect research. On the other hand the transparent larger crystals seem to be rather pure and can be considered for this purpose. However, a close examination of these larger crystals by means of a Weisenberg photograph showed that these crystals in general appeared to consist of layers stacked irregularly around the $c_{\mathrm{h}}$-axis.

Taking all these results together it can be said that these compounds are less attractive for a further study of their defect properties.

2. Geometrical consideration of the $\alpha-\mathrm{NaFeO}_{2}$ structure. - The X-ray data which were obtained from powders prepared in this laboratory agreed well with those reported by Ballestracci [2] and Tromme [3]. Some of these values are collected in table I.

An inspection of table I reveals that the hexagonal $c_{\mathrm{h}}$-axis is quite independent of the radius of the tri- 
TABLE I

Observed lattice constants in $\mathrm{TMS}_{2}$ compounds [2]

\begin{tabular}{|c|c|c|}
\hline Compound & $a_{\mathrm{h}}(\Lambda)$ & $c_{\mathrm{b}}(\AA)$ \\
\hline - & - & - \\
\hline $\mathrm{NaNdS}_{2}$ & 4.100 & 19.90 \\
\hline $\mathrm{NaEuS}_{2}$ & 4.042 & 19.92 \\
\hline $\mathrm{NaGdS}_{2}$ & 4.009 & 19.87 \\
\hline $\mathrm{NaDyS}_{2}$ & 3.978 & 19.92 \\
\hline $\mathrm{NaHoS}_{2}$ & 3.949 & 19.86 \\
\hline $\mathrm{NaErS}_{2}$ & 3.939 & 19.98 \\
\hline $\mathrm{NaYbS}_{2}$ & 3.902 & 19.91 \\
\hline $\mathrm{LiHoS}_{2}$ & 3.898 & 18.68 \\
\hline $\mathrm{NaHoS}_{2}$ & 3.949 & 19.86 \\
\hline $\mathrm{KHOS}_{2}$ & 4.010 & 21.80 \\
\hline
\end{tabular}

valent ion for a given alkali ion. This independence will be used to arrive at a mathematical expression for the hexagonal $a_{\mathrm{h}}$ - and $c_{\mathrm{h}}$-axes in terms of the deformation of the octahedra around the cations, as will be shown below.

2.1 Calculation of THE $a_{\mathrm{h}}$ - AND $c_{\mathrm{h}}$-AXES FOR THE ORDERED $\alpha-\mathrm{NaFeO}_{2}$ STRUCTURE. - In the hexagonal structure of the space group $\mathrm{R} \overline{3} \mathrm{~m}$ the cations occupy all the octahedral sites formed by the cubic sulfur packing. So, the crystal structure may be considered to be built up of $\mathrm{TS}_{6}$ and $\mathrm{MS}_{6}$ octahedra (Fig. 1) which may be trigonally deformed along the $c_{\mathrm{h}}$-axis. In the following calculation of the $a_{\mathrm{h}}$ - and $c_{\mathrm{h}}$-axes use is made of the rigid ion model, as well as of the assumption that the sulfur ions do not touch each other.

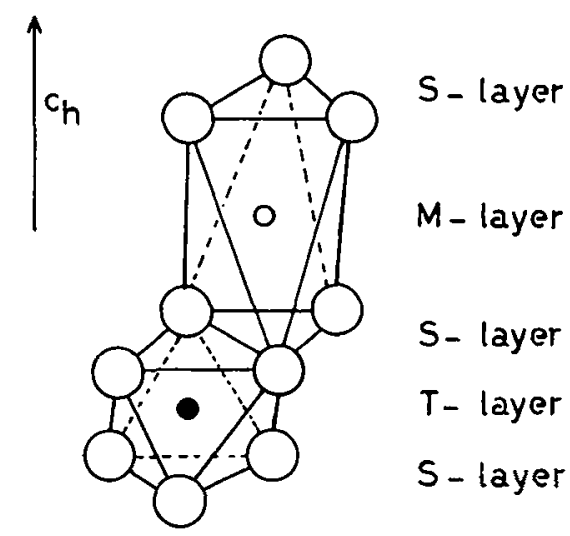

Fig. 1. - Schematic view of the layer structure of compounds belonging to the class $\alpha-\mathrm{NaFeO}_{2}(\mathrm{R} \overline{3} \mathrm{~m})$. In the figure the two octahedra $\mathrm{TS}_{6}$ and $\mathrm{MS}_{6}$ are indicated. It is assumed that the sulfur ions do not touch each other. $\mathrm{T}=$ trivalent rare earth ion, $\mathrm{M}=$ monovalent alkali ion, $\mathrm{S}=$ sulfur ion.

Suppose now that the crystal contains only M-cations, then the crystal can be built up $\mathrm{MS}_{6}$ octahedra only. In figure 2 one of the $\mathrm{MS}_{6}$ octahedra is

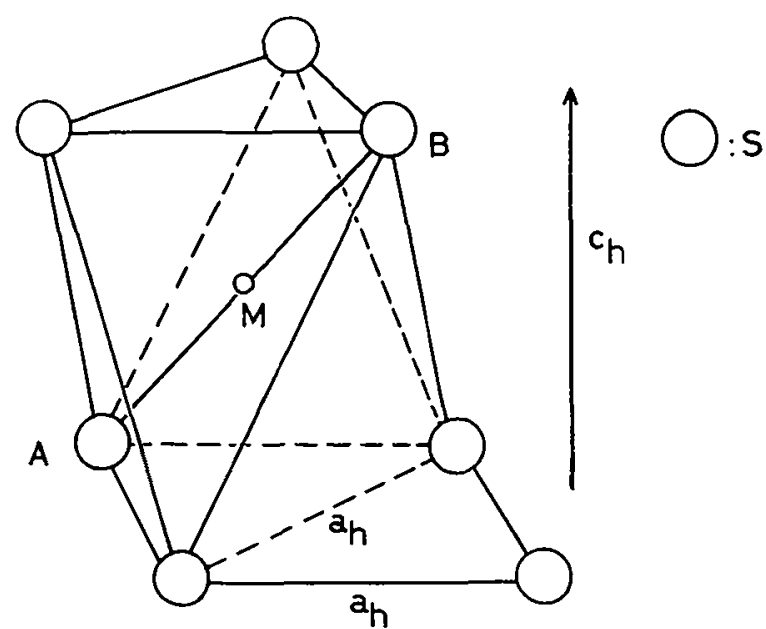

FIG. 2. - Ideal $\mathrm{MS}_{6}$ octahedron indicating the relation between the hexagonal $a_{\mathrm{h}}$-axis and the body diagonal $A B$.

sketched which is considered to be ideal. It follows that for this ideal $\mathrm{MS}_{6}$ octahedron :

$$
\left.\begin{array}{l}
A B=2 r^{+}+2 r^{2-} \\
A B=a_{\mathrm{h}} \sqrt{2}
\end{array}\right\} \text { so } a_{\mathrm{h}}=\sqrt{2}\left(r^{+}+r^{2-}\right) .
$$

Similarly when the crystal contains only rare earth ions, it is found that for an ideal $\mathrm{TS}_{6}$ octahedron $a_{\mathrm{h}}$ is given by

$$
a_{\mathrm{h}}=\sqrt{2}\left(r^{3+}+r^{2-}\right) .
$$

As the real compound is built up for both octahedra a weighted average is used:

$$
a_{\mathrm{h}}=\sqrt{2}\left(a r^{3+}+b r^{+}+r^{2-}\right)
$$

in which the parameters $a$ and $b$ satisfy the relation

$$
a+b=1 \text { with } a>b
$$

and where $a$ and $b$ not only represent the contribution of the respective octahedra, but also make allowance for deformation. In the ideal case i. e. when $r^{+} \approx r^{3+}$ (this implies that the S-atoms are located at the exact $z=0.25$ position) and also $r^{+} \approx \frac{1}{2} r^{2-}, a=\frac{3}{4}$ and $b=\frac{1}{4}$ on account of the $3 \times$ stronger Coulomb attraction of the rare earth ion. So, deviations from these values constitute a measure of the deformation of the octahedra.

A similar expression for the $c_{\mathrm{h}}$-axis can be deduced from a close inspection of figure 3 . First it must be noted that the $c_{\mathrm{h}}$-axis is equal to $6 \times$ the distance between successive sulfur layers:

$$
c_{\mathrm{h}}=6\left(l_{1}+l_{2}\right)
$$

where $l_{1}$ and $l_{2}$ are the distances between an $\mathbf{M}$-ion and the sulfur layer and a $\mathrm{T}$-ion and the sulfur layer respectively. 


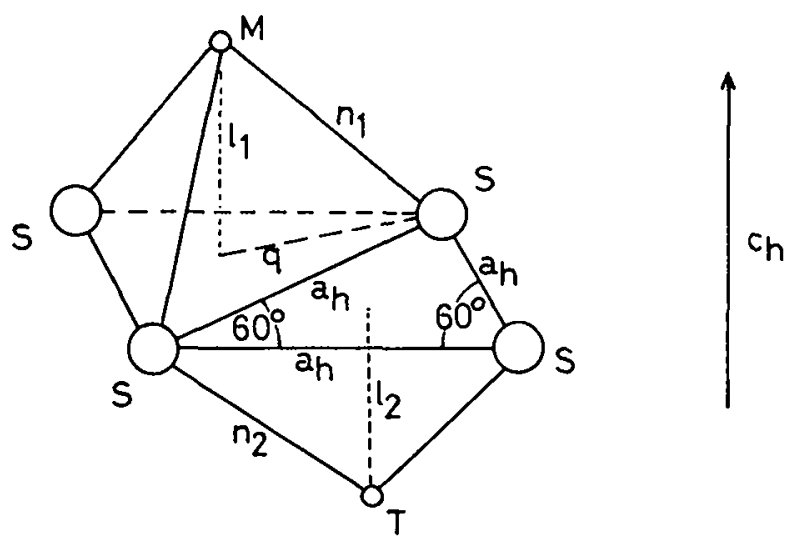

Fig. 3. - Calculation of the hexagonal $c_{\mathrm{n}}$-axis from gcometrical considerations. $c_{\mathrm{h}}=6\left(l_{1}+l_{2}\right) . \mathrm{M}=$ alkali ion, $\mathrm{T}=$ rare earth ion, $\mathbf{S}=$ sulfur ion.

$l_{1}$ satisfies

$$
l_{1}=\sqrt{n_{1}^{2}-q^{2}}
$$

with

$$
n_{1}=r^{2-}+r^{+}
$$

and

$$
q=\frac{1}{\sqrt{3}} a_{\mathrm{h}}
$$

similarly

$$
l_{2}=\sqrt{n_{2}^{2}-\overline{q^{2}}}
$$

with

$$
n_{2}=r^{2-}+r^{3+} .
$$

Substitution of eq. (4-8) and 1 in relation (3) results in

$$
\begin{aligned}
& c_{\mathrm{h}}= 6 \sqrt{\left(r^{+}+r^{2-}\right)^{2}-\frac{2}{3}\left(a r^{3+}+b r^{+}+r^{2-}\right)^{2}}+ \\
&+\sqrt{\left(r^{3+}+r^{2-}\right)^{2}-\frac{2}{3}\left(a r^{3+}+b r^{+}+r^{2-}\right)^{2}} .
\end{aligned}
$$

In the expression for the $a_{\mathrm{h}}$-axis (eq. (1)) as well as in the expression for the $c_{\mathrm{h}}$-axis (9) the parameters $a$ and $b$ depend on the actual values of $r^{3+}$ and $r^{+}$. However, both expressions can be solved for $a$ and $b$ by using the independence of the $c_{\mathrm{h}}$-axis on $r^{3+}$ for fixed $r^{+}$as is found experimentally (see Table I). Thus, besides relation (2): $a+b=1$, another relation exists viz.

$$
\left[\frac{\partial c_{\mathrm{h}}}{\partial r^{3+}}\right]_{r^{+}}=0
$$

(1) The observed independence of $c_{h}$ in a series $\mathrm{NaTS}_{2}$, LiTS $_{2}$ or $\mathrm{KTS}_{2}$ can physically be understood from figurc 1. When a $\mathrm{T}^{3+}$ ion is replaced by a bigger one this has two effects on $c_{\text {n }}$. Firstly a positive contribution by virtue of its larger radius, but secondly a negative contribution because the sulfur ions are forced apart, where upon the alkali ion in the neighbouring octahedron can take a lower position between the sulfur ions. Both effects apparently cancel each other.
Now the relevant relations can be solved. The actual calculation is done by means of a small computer program. To obtain the absolute values of $a_{\mathrm{h}}, c_{\mathrm{h}}$, $a$ and $b$ use was made of the ionic radii for the rare earth ions as given by Ballestracci [2]. The sulfur radius was taken to be $1.82 \AA$ while for the radii of the alkali-ions the following values were used :

$$
r_{\mathrm{Li}^{+}}=0.89 \AA, \quad r_{\mathrm{Na}^{+}}=1.09 \AA, \quad r_{\mathrm{K}^{+}}=1.38 \AA
$$

(these values were obtained for the ternary sulfides by means of an analysis given in appendix 1).

Some calculated results for the $a_{\mathrm{h}}$-axis and the parameters $a$ and $b$ are collected in table II, while a complete survey for $a_{\mathrm{h}}$ is given in figures 4 and 5 .

\section{TABLE II}

Calculated and experimental results on the hexagonal $a_{\mathrm{h}}$-axis for some ternary sulfides. $a$ and $b$ are the coefficients in the theoretical relation for $c_{\mathrm{h}}$ (eq. (9)). For the ideal case $a=0.75, b=0.25$.

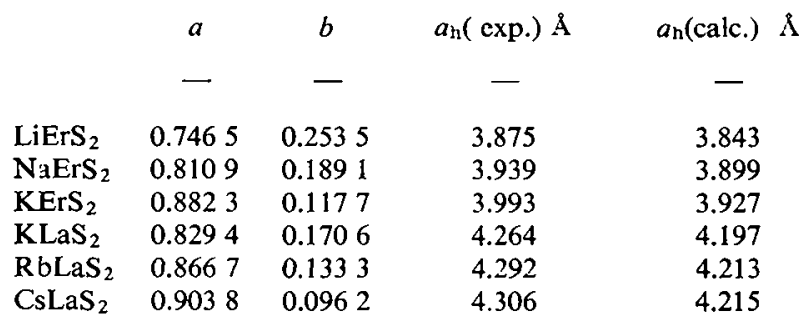

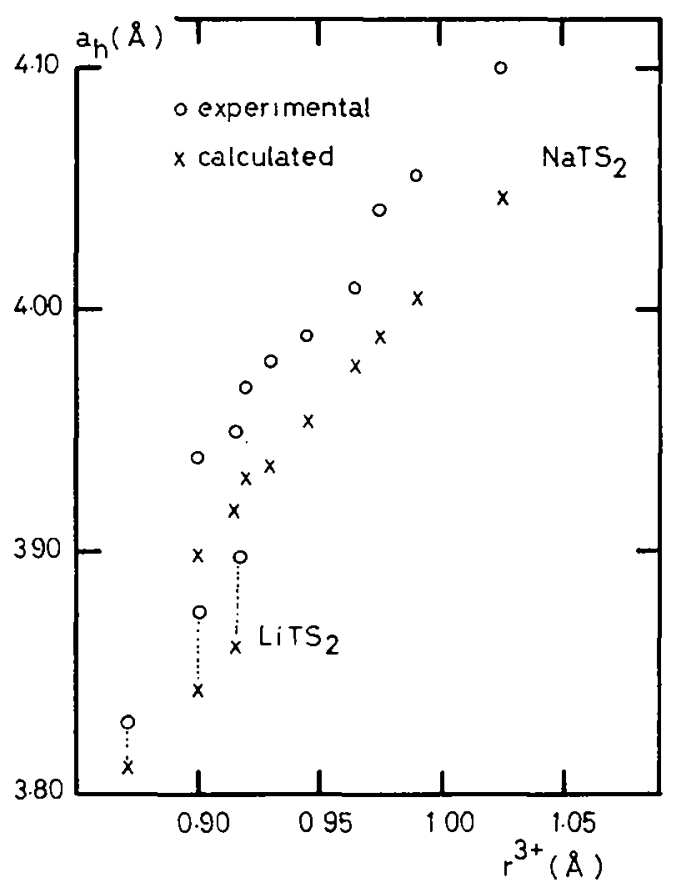

FIG. 4. - Calculated and experimental results of the hexagonal

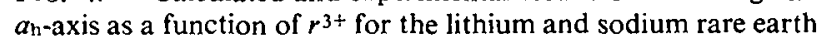
sulfides. 


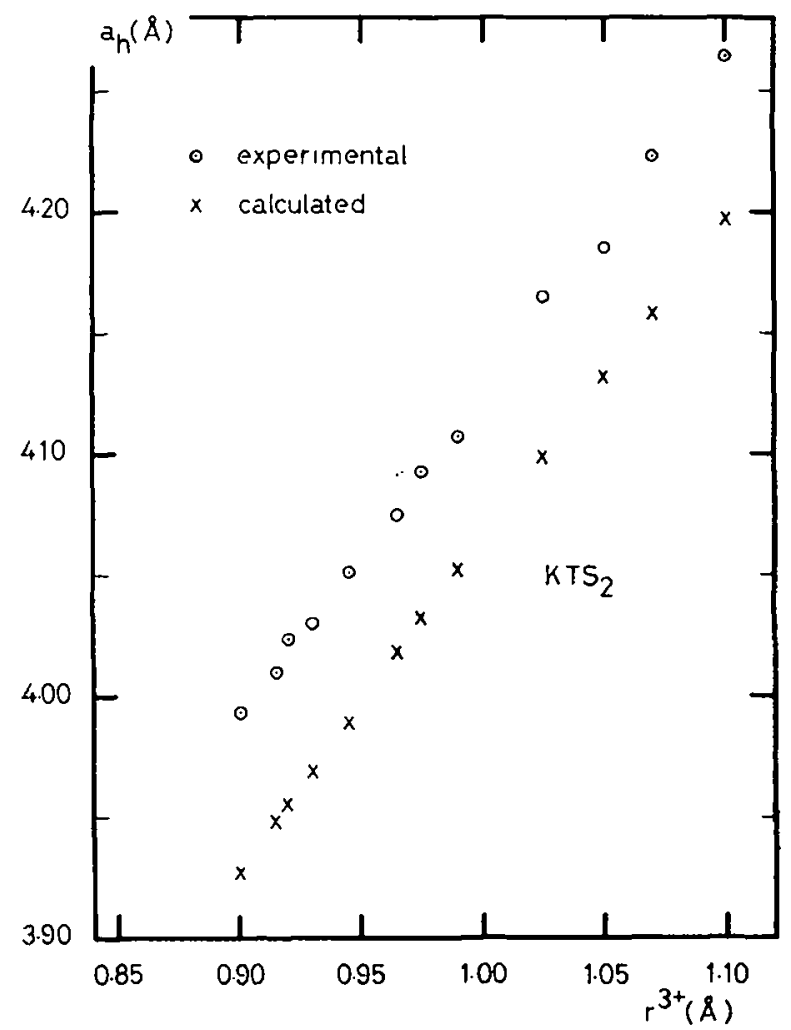

Fig. 5. - Calculated and experimental results of the hexagonal

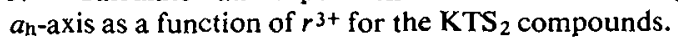

It is to be noted that all the calculated values are consistently low, about $1.5 \%$ for the $\mathrm{Na}$-compounds, $2.6 \%$ for the $\mathrm{K}$-compounds, and less than $1 \%$ for the Li-compound. The agreement between calculated and experimental values can considered to be good, especially if the large apparent inaccuracy in the rare earth ion radii is taken into account.

In figure 6 the hexagonal $c_{\mathrm{b}}$-axis is plotted as function of the alkali radii for the erbium sulfides, according to eq. (9), the largest deviation in this case is $3.7 \%$, again well within the accuracy of the ionic radii. From the figure it is clear that the slope of the experimental and calculated curves are in reasonable agreement. In the same figure the slope predicted by Brunel [10] is given, which differs substantially.

In table III the deformation ratio $\alpha$, defined as $\alpha=a / b$, for some compounds is collected together with the ratio $r^{3+} / r^{+}$. There is a direct connection between both values, as is clear from figure 7. For $\mathrm{LiErS}_{2}$ with $r^{+} \approx r^{3+} \alpha$ is found to be 0.34 , which is very close to the ideal value $\alpha=\frac{1}{3}$. A calculation of $\alpha$ for all the existing ternary sulfides with $\mathrm{R} \overline{3} \mathrm{~m}$ symmetry shows that the $\alpha-\mathrm{NaFeO}_{2}$ structure occurs for $0.35<\alpha<0.10$.

2.2 Calculation of THE SUlfur Shifr. - In the space group $R \overline{3} \mathrm{~m}$ the sulfur atoms occupy the positions $\left(0,0, \frac{1}{4}+\varepsilon\right),\left(0,0, \frac{3}{4}-\varepsilon\right)$ and symmetry

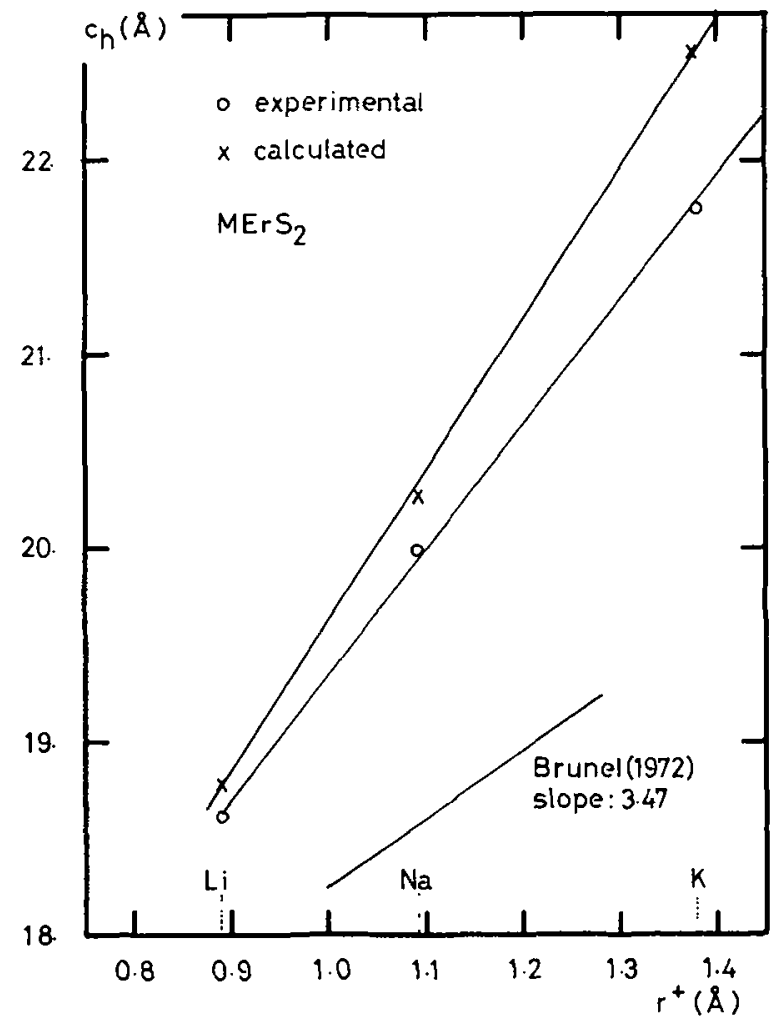

FIG. 6. - Calculated and experimental values for the $c_{\mathrm{n}}$-axis for $\mathrm{Li}, \mathrm{Na}$ and $\mathrm{KErS}_{2}$. For comparison also the slope is given which is used by Brunel [10].

TABLE III

The deformation constant $\alpha=b / a$ and the ratio $r^{3+} / r^{+}$for some ternary sulfides

$\begin{array}{lcc} & \alpha & r^{3+} / r^{+} \\ \mathrm{LiErS}_{2} & - & - \\ \mathrm{NaErS}_{2} & 0.3395 & 1.01 \\ \mathrm{KLaS}_{2} & 0.2332 & 0.82 \\ \mathrm{RbLaS}_{2} & 0.2057 & 0.80 \\ \mathrm{CsLaS}_{2} & 0.1540 & 0.71 \\ & 0.1064 & 0.64\end{array}$

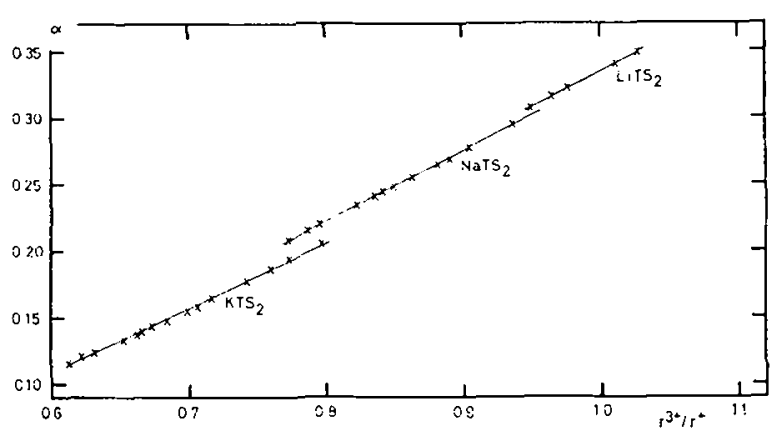

FiG. 7. - Calculated deformation constant $\alpha$ (defined by $\alpha=b / a)$ versus $r^{3+} / r^{+}$for the lithium, sodium and potassium ternary sulfides. 
related positions. In this notation $\varepsilon$ is the $z$-shift of the sulfur ion from the ideal positions $\left(0,0, \frac{1}{4}\right)$ and $\left(0,0, \frac{3}{4}\right)$ and is defined by

$$
\varepsilon=\frac{\delta z}{c_{\mathrm{h}}}
$$
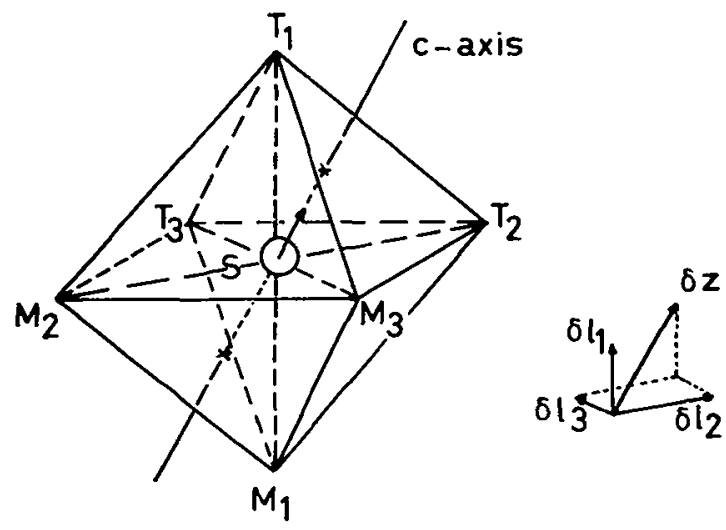

$$
\delta \bar{z}=\delta \vec{l}_{1}+\delta \vec{I}_{2}+\delta \vec{l}_{3}
$$

Fig. 8. - $(\mathrm{MT})_{3} \mathrm{~S}$ octahedron indicating the total shift $\delta z$ along the hexagonal $c_{\mathrm{h}}$-axis. $\delta z$ is composed of the partial shifts $\delta l_{\mathrm{i}}$ along the body diagonals according to

$$
\delta z=\delta \mathbf{l}_{1}+\delta \mathbf{I}_{2}+\delta \mathbf{I}_{3} .
$$

Because of the difference in $r^{+}$and $r^{3+}$ the sulfur atoms move from the ideal position along the hexagonal $c_{\mathrm{b}}$-axis. The total shift $\delta z$ is composed of the three partial shifts $\delta l_{\text {; }}$ along the 3 body diagonals MT. From figure 8 it follows

$$
\begin{array}{r}
\delta l_{1}=\frac{\mathrm{M}_{1} \mathrm{ST}_{1}}{2}-\mathrm{ST}_{1}=\frac{r^{+}+2 r^{2-}+r^{3+}}{2} \\
-\left(r^{2-}+r^{3+}\right)=\frac{r^{+}-r^{3+}}{2} .
\end{array}
$$

The total shift $(\delta z)$ is found as the vector sum of $\delta \mathbf{l}_{1}+\delta \mathbf{l}_{2}+\delta \mathbf{l}_{3}$ leading to

$$
\delta z=\delta l \sqrt{3}=\frac{1}{2} \sqrt{3}\left(r^{+}-r^{3+}\right)
$$

where the assumption is made that the octahedron given in figure 8 can be taken as ideal. This is only permitted in a first order calculation, but it is allowed for the small correction $\delta z$ on the total $z$-parameter. Inserting (12) into eq. (10) leads to

$$
\varepsilon=\frac{1}{2} \sqrt{3} \frac{\left(r^{+}-r^{3+}\right)}{c_{\mathrm{h}}} .
$$

It is possible to use either the experimental or the calculated $c_{\mathrm{h}}$ values to get $\varepsilon$, because $\varepsilon$ is not sensitive to small changes in $c_{h}$. In most calculations it is even sufficient to assume that in eq. (9) $r^{+} \approx r^{3+}$. Inserting this in (13) leads to the simple expression

$$
\varepsilon=\frac{1}{8}\left(\frac{r^{+}-r^{3+}}{r^{+}+r^{2-}}\right) .
$$

A similar derivation has been given by Brunel [10] who arrived at the expression

$$
4 \varepsilon=1-\frac{2\left(r^{3+}+r^{2-}\right)}{r^{3+}+r^{+}+2 r^{2+}} .
$$

The difference between both equations actually appears to be very small. In table IV some experimental $\varepsilon$ values are compared with calculated ones according to relation (13) by using experimentally observed $c_{\mathrm{h}}$ values in the calculation. The agreement is quite satisfactory.

TABLE IV

\section{Observed and calculated sulfur shifts} in $\mathrm{TMS}_{2}$ compounds

\begin{tabular}{lllcc} 
& \multicolumn{1}{c}{$z_{\text {obs }}$} & \multicolumn{1}{c}{$\varepsilon_{\text {obs }}$} & $\varepsilon_{\text {calc }}$ & subscript \\
$\mathrm{KNdS}_{2}$ & $0.2647(5)$ & 0.015 & 0.014 & - \\
$\mathrm{NaCrS}_{2}$ & $0.2662(4)$ & 0.016 & 0.015 & 2 \\
$\mathrm{NaCrS}_{2}$ & 0.264 & 0.014 & 0.015 & 3 \\
$\mathrm{NaInS}_{2}$ & 0.26 & 0.01 & 0.007 & 3 \\
$\mathrm{NaErS}_{2}$ & 0.258 & 0.008 & 0.008 & 4
\end{tabular}

1. $z_{\text {obs }}$ from neutron diffraction this work,

2. $z_{\text {ous }}$ from neutron diffraction, ref. [11],

3. values from $X$-ray studies, ref. [5],

4. values from $X$-ray studies, ref. [1].

In table IV some values of $\varepsilon$ were deduced from neutron diffraction spectra obtained from powders. Normally the $z$-shift is calculated from single crystal diffraction data, but this was not possible for these ternary sulfides because most of the crystals consisted of a stack of layers twisted irregularly around the $c_{\mathrm{b}}$-axis. Some efforts were made to calculate the value of the $z$-shift from a one-dimensional Fourier synthesis on the X-ray powder diagram. This method appears to have several disadvantages. Firstly the accuracy in the $z$-position is completely governed by the experimental error with which the intensities of the $(0,0, l)$ reflections - especially those with large $l$ - can be determined. A second disadvantage is the persistent occurrence of a preferred orientation for these layer structures in the powdered sample, which hampers a correct interpretation of the spectra. These disadvantages are less tedious in neutron diffraction experiments of powders because of the deeper penetration of the neutrons in the sample and because the atomic scattering factor for neutrons is independent of $\sin \theta / \lambda$. Therefore all the lines in the diffraction pattern can be used 
to calculate the $z$-position. The actual calculation and refinement of this parameter were done according to the line profile method described by Rietveld [12]. The refinement was taken over those lines which were not overlapped by the impurity lines belonging to the oxysulfide.

3. Conclusion. - The ternary sulfides of the type $\mathrm{KLaS}_{2}$ can be made in a reproducible way by means of flux methods. The quality of the endproduct depends on the rare earth which is being used. In almost all ternary sulfides the oxysulfide $\mathrm{T}_{2} \mathrm{O}_{2} \mathrm{~S}$ is present in concentrations which are too high to permit a deeper study of the defect chemistry.

A geometrical analysis is given which is based on the independence of the $c_{\mathrm{h}}$-axis on the rare earth radii for a given alkali radius, and which also takes into account the relative sizes of the $\mathrm{TS}_{6}$ and $\mathrm{MS}_{6}$ octahedra on the crystal parameters. This model gives satisfactory results when the calculated values for the $a_{\mathrm{h}}$ and $c_{\mathrm{b}}$ axes and the calculated value for the $z$-shift are compared with the experimental ones.

Acknowledgments. - The present investigations have been carried out under the auspices of the Netherlands Foundation for Chemical Research (S. O. N.) and with the financial aid from the Netherlands Organisation for the Advancement of Pure Research (Z. W. O.).

The authors further wish to thank Dr. Bergsma of the Reactor Centre RCN Petten, the Netherlands, for his assistance in the neutron diffraction experiments.

Appendix I. - The distance between two points $\left(x_{1}, y_{1}, z_{1}\right)$ and $\left(x_{2}, y_{2}, z_{2}\right)$ in a trigonal lattice is given by the general relation:

$$
d=\frac{3}{4} \sqrt{a_{\mathrm{h}}^{2} \Delta y^{2}+a_{\mathrm{h}}^{2}\left(\Delta x-\frac{1}{2} \Delta y\right)^{2}+c_{\mathrm{h}}^{2} \Delta z} .
$$

The alkali atom (M) occupies the position $\left(0,0, \frac{1}{2}\right)$ while the neighbouring sulfur atom (S) is located at $\left(\frac{2}{3}, \frac{1}{3}, \frac{7}{12}+\varepsilon\right)$, so that the distance between them becomes :

$$
\mathrm{MS}=\sqrt{\frac{1}{3} a_{\mathrm{h}}^{2}+c_{\mathrm{h}}^{2}(0.083+\varepsilon)^{2}}
$$

MS also satisfies the relation:

$$
\mathrm{MS}=r^{+}+r^{2-} \text {. }
$$

From both relations it follows that:

$$
r^{+}=\sqrt{\frac{1}{3} a_{h}^{2}+c_{h}^{2}(0.083+\varepsilon)^{2}}-r^{2-} .
$$

The alkali radius can now be calculated by using experimental values for $a_{\mathrm{h}}, c_{\mathrm{h}}$ and $\varepsilon$ (or the equivalent theoretical expression) and $r^{2-}=1.82 \AA$ (Table V).

\section{TABLE V}

\section{Calculated alkali radii for the ternary sulfides according} to eq. (15)

$\begin{array}{lc} & r^{+}(\AA) \\ \mathrm{Li}^{+} & - \\ \mathrm{Na}^{+} & 0.89 \\ \mathrm{~K}^{+} & 1.09 \\ \mathrm{Rb}^{+} & 1.38 \\ \mathrm{Cs}^{+} & 1.54 \\ & 1.72^{5}\end{array}$

The calculated values are in good agreement with values given in reference $[1,2]$, except for lithium which is somewhat smaller.

\section{References}

[1] Ballestracci, R. and Bertaut, E. F., Bull. Soc. Miner Crist. 87 (1964) 512.

[2] Ballestracci, R. and Bertaut, E. F., Colloques internationaux du C. N. R. S. Orsay 28 sept. -1 oct. 1965 , p. 41-49.

[3] Tromme, M., C. R. Hebd. Séan. Acad. Sci. Série C 273 (1971) 849 .

[4] Bronoer, W., Elter, R., Maus, E. and Schmitt, T., Rev. Chim. Miner. 10 (1973) 147.

[5] Brüesch, P. and Schüler, C., J. Phys. Chem. Solids 32 (1971) 1025.
[6] Schüfer, H., Z. Anorg. Allg. Chem. 403 (1974) 116.

[7] Netherlands Standard, NEN 3103 (1972).

[8] Eastman, E., Brewer, L. and Bromley, L., J. Am. Chem. Soc. 72 (1950) 2248.

[9] Eastman, E., Brewer, L. and Bromley, L., J. Am. Chem. Soc. 73 (1951) 3896.

[10] Brunel, M., De Bergevin, F. and Gondrand, M., J. Phys. Chem. Solids 33 (1972) 1927.

[11] Enoelsman, F. M. R., Thesis 1974, University of Groningen, the Netherlands.

[12] Rietveld, H. M., J. Appl. Crystallogr. 2 (1969) 65. 